Journal of Advanced Research in Fluid Mechanics and Thermal Sciences

Journal homepage: www.akademiabaru.com/arfmts.html ISSN: $2289-7879$

\title{
Homann Stagnation Point Flow and Heat Transfer of Hybrid Nanofluids Over a Permeable Radially Stretching/Shrinking Sheet
}

\author{
Yap Bing Kho ${ }^{1}$, Rahimah Jusoh ${ }^{1,}{ }^{*}$, Mohd Zuki Salleh ${ }^{1}$, Mohd Hisyam Ariff ${ }^{2}$, Ioan Pop ${ }^{3}$ \\ 1 Centre for Mathematical Sciences, College of Computing and Applied Sciences, Universiti Malaysia Pahang, Lebuhraya Tun Razak, 26300 \\ Gambang, Kuantan, Pahang, Malaysia \\ 2 Faculty of Electrical \& Electronics Engineering Technology, Universiti Malaysia Pahang, 26600 Pekan, Pahang, Malaysia \\ 3 Department of Mathematics, Babeş-Bolyai University, R-400084 Cluj-Napoca, Romania
}

\section{$\begin{array}{ll}\text { ARTICLE INFO } & \text { ABSTRACT }\end{array}$}

\section{Article history:}

Received 26 April 2021

Received in revised form 20 June 2021

Accepted 23 June 2021

Available online 1 August 2021

\begin{abstract}
The steady two-dimensional Homan stagnation point flow and heat transfer of water base hybrid nanofluids $\left(\mathrm{Al}_{2} \mathrm{O}_{3} \& \mathrm{Cu}\right)$ over a permeable radially stretching/shrinking sheet have been studied. The similarity variables are introduced to transform the partial differential equations of the model into the ordinary differential equations. Numerical findings and dual solutions have been carried out by implementing the bvp4c code through MATLAB software. The most prominent effect is illustrated in the boundary layer thickness where the velocity profile increases upon the increment of the suction intensity but decreases in the temperature profile. Besides, the reduced Nusselt number also decreases as enlarging the value of copper and alumina nanoparticle volume fraction. The analysis of the first and second solutions are presented graphically with critical values as well as the detail discussions on the effects of the other involving parameters.
\end{abstract}

Keywords:

Hybrid nanofluid; Homann stagnation point flow; dual solutions

\section{Introduction}

The properties of heat transfer rate are always the attractive scope of research in fluid dynamics analysis. Since the conventional fluid has weak performance in the thermal conductivity, thus it has been alternatively replaced by the fluid that's more desirable and satisfactory, called nanofluid [1,2]. The discovery of nanofluid was coined by Choi and Eastman [3] who introduce it as an ideal solution to replace the conventional fluid for enhancing the thermal conductivity. Hence, intrigued by the numerous applications of nanofluids in diverse industries like power plant cooling system, microelectronics, chemical engineering and so on, many researchers have work on the uniqueness of nanofluids [4-8].

However, lately the researchers have noticed that the nanofluids no longer to meet all the necessity in heat transfer properties. The inadequacy of conventional heat transfer nanofluids containing a single type of nanoparticle leads to the invention of hybrid nanofluid. As the extension

\footnotetext{
* Corresponding author.

E-mail address: rahimahj@ump.edu.my

https://doi.org/10.37934/arfmts.85.1.101112
} 
work from nanofluids, the hybrid nanofluids are created with the amalgamation of distinct types of nanoparticles in the base fluid. The matches of different nanoparticles enable the great performance in thermal characteristics as well as ultimately increase the heat transfer rate. These were supported by many researchers after studied and investigated the attribute and behaviour of nanofluids in different aspects. Kumar and Arasu [9] claimed that composite nanoparticles exhibited superior improvement in rheological and thermal features of the conventional fluid compared to the single type nanoparticle after carried out the experimental research about stability, characterization and properties of $\mathrm{Al}_{2} \mathrm{O}_{3}-\mathrm{Cu}$ hybrid nanofluids. Also, Hayat and Nadeem [10] claimed that the performance of Ag-CuO hybrid nanofluid in heat transfer is better than the mono-particle nanofluid. Hybrid nanofluids can be used in numerous conceivable applications in most of heat transfer fields like acoustics, manufacturing, micro fluidics etc. Due to the synergistic effect of choosing a proper combination of different nanoparticles and as the nanoparticles are being disseminate pertinently, it could lead to provide the exceptional high effective thermal conductivity. An extensive study on the related field had been done by a few researchers [11-13]. Sinz et al., [14] discovered an increment of heat transfer rate in the turbulent force convective model of silver-graphene hybrid nanofluid as Reynolds number increases. The comprehensive review on the preparation methods of hybrid nanofluid with its properties and performance had been carried out by Xian et al., [15] and Urmi et al., [16]. Azman et al., [17] compared the heat transfer performance between the mono nanofluid (single nanoparticle) and hybrid nanofluid (two nanoparticles, $\mathrm{Al}_{2} \mathrm{O}_{3}-\mathrm{Cu}$ ) in a straight pipe. They found that the percentage of mono nanofluid heat transfer was slightly higher than the hybrid nanofluid. In contrast, Idris et al., [18] discovered that the hybrid nanofluid $\left(\mathrm{Al}_{2} \mathrm{O}_{3}-\mathrm{SiO}_{2}\right)$ improved the single nanofluid performance in the cooling plate of fuel cells.

The heat transfer and fluid flow due to stretching plate is one of the crucial parts in the applications like metal or fibre spinning manufacturing, paper production, plastic films, glass blowing and etc. The amount of heat transfer at the stretching surfaces is directly affecting the quality of the final products as mentioned by Roşca and Pop [19]. The first problem which involved the boundary layer flow on a continuous object's surface was studied by Sakiadis [20], followed by Crane [21] who studied the flow past a stretching plate. He came out with the exact analytical solution for the steady two-dimensional flow over a stretching surface. Thus, this has inspired many researchers to consider stretching sheet or plate in their boundary layer study. The stretching flow can be identified as a circumstance when the fluid at the boundary moves away from a fixed point whereas if the movement of the fluid against the direction of the flow, then it is called shrinking flow. Miklavčič and Wang [22] proved the existence of non-uniqueness solution of the fluid flow owing to a shrinking sheet. After several years, most of the researchers considered both stretching/shrinking sheet in their studies. The stagnation-point flow over a stretching/shrinking sheet in a nanofluid was analysed by Bachok et al., [23]. Then, Waini et al., [24] investigated the unsteady flow and heat transfer of hybrid nanofluid past a stretching/shrinking sheet. The solutions for greater shrinking impermeable sheet will never exist since the vorticity could not be cramped in the boundary layer. However, if there is the stagnation flow to restrain the vorticity, thus the similarity solutions are likely to exist.

The problem which involved the two-dimensional stagnation-point flows was pioneered by Hiemenz [25]. The flow of stagnation point can be defined as the flow about the front of a bluntnosed body or the stagnation division, happen on bodies moving in a fluid. Moreover, the stagnation point meets unexpectedly the highest rates of mass deposition, the topmost heat transfer as well as the pressure. Then, Homann [26] studied the problem of stagnation-point flow in axisymmetric case. Afterwards, the study of numerous aspects of stagnation-point flow in large scale garnered considerable attention which correspond to the viscous fluid flow and different geometry like stretching/shrinking plate and wavy cylinder. Yousefi et al., [27] investigated the steady general 
three-dimensional stagnation-point flow of an aqueous $\mathrm{TiO}_{2}-\mathrm{Cu}$ hybrid nanofluid toward a wavy cylinder analytically. Besides, Ghalambaz et al., [28] studied the mixed convection and stagnation point flow and heat transfer of $\mathrm{Al}_{2} \mathrm{O}_{3}-\mathrm{Cu}$ /water hybrid nanofluid over a vertical plate. The simultaneous effects of wall transpiration through a radially stretching on Homann stagnation point flow was reported by Weidman and Ma [29]. They mentioned that the blowing must be less than zero while suction must be greater than zero. Recently, Mahapatra and Sidui [30] investigated the non-axisymmetric Homann stagnation-point flow of a viscoelastic fluid past a rigid plate and concluded that the fluid's viscoelasticity delayed the reverse flow at the wall.

Motivated by the above researches, the present studies intend to theoretically carry out numerical solutions of Homann stagnation point flow and heat transfer of $\mathrm{Al}_{2} \mathrm{O}_{3}-\mathrm{Cu}$ hybrid nanofluids past a permeable radially stretching/shrinking sheet. The novelty of our work is focus on the dual solutions of Homann stagnation point flow of hybrid nanofluid. This topic yet to fully explored and discovered and it is important to imply in the specific field as mentioned above. Since some of the researchers only provide a single solution for particular problem, thus may have resulted in a lack of persuasion and cause the explanation looks insubstantial. By performing the dual solutions, we are able to see the differences of the two obtained results and enable to give adequate explanation for conviction about the behaviour of hybrid nanofluids flow. The graphical results are presented and plotted, then discussed in the next sections.

\section{Mathematical Model}

In this study, the model of steady two-dimensional Homann stagnation point flow and heat transfer of the water base hybrid nanofluid over a permeable stretching/shrinking sheet is considered as displayed in Figure 1 with the cylindrical coordinates $(r, \Omega, z)$. Here, the plat is reflected by the $r$ axis and $z$ axis is perpendicular to it. All the physical quantities are not depending on the angle $\Omega$ since it is rotational symmetry. It is assumed that $u_{w}(r)$ is representing the velocity of the stretching/shrinking sheet. In addition, $\left(u_{e}(r), 0,0\right)$ is the velocity of the far field (inviscid flow). As further information, the constant temperature of the surface of the sheet is denoted by $T_{w}$ while $T_{\infty}$ represents the temperature of the far field. Since this study focus on hybrid nanofluid, thus a few assumptions need to be done which are considering the uniformity size of nanoparticles and neglecting the impact of the nanoparticle's agglomeration. This is due to the synthetization of the nanofluids as a stable mixture of the base fluid and nanoparticles. Therefore, with these physical assumptions, we consider the cylindrical coordinates $(r, 0, z)$ of the governing equations of the Homann stagnation flow of hybrid nanofluid as follows [29,31]: 


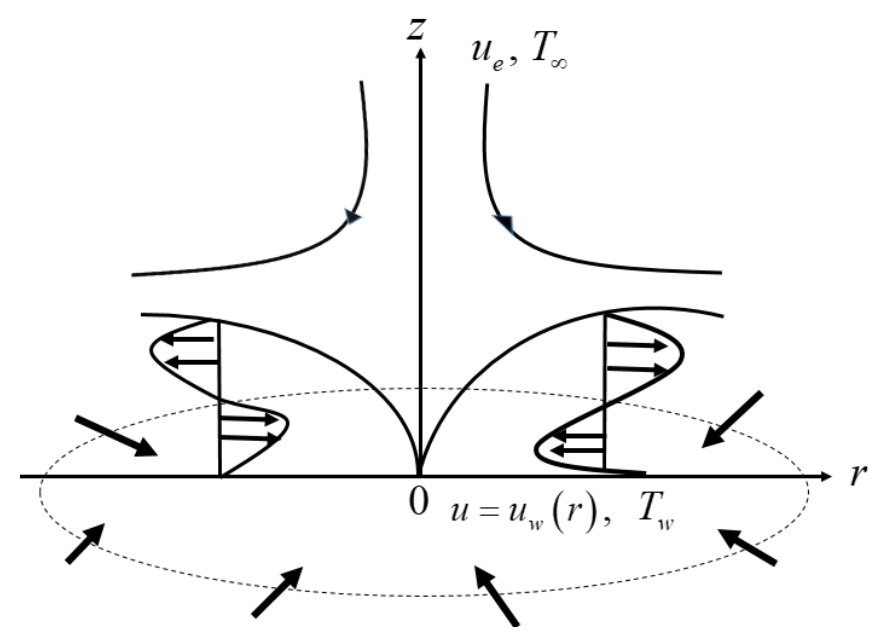

Fig. 1. Physical model of the Homann stagnation point flow of hybrid nanofluid over a radially shrinking sheet $(\lambda<0)$

$\frac{\partial}{\partial r}(r u)+\frac{\partial}{\partial z}(r w)=0$

$u \frac{\partial u}{\partial r}+w \frac{\partial u}{\partial z}=-\frac{1}{\rho_{h n f}} \frac{\partial \rho}{\partial r}+\frac{\mu_{h n f}}{\rho_{h n f}}\left(\frac{\partial^{2} w}{\partial r^{2}}+\frac{1}{r} \frac{\partial u}{\partial r}+\frac{\partial^{2} u}{\partial z^{2}}-\frac{u}{r^{2}}\right)$

$u \frac{\partial T}{\partial r}+w \frac{\partial T}{\partial z}=\frac{k_{h n f}}{\left(\rho C_{\rho}\right)_{h n f}}\left(\frac{\partial^{2} T}{\partial r^{2}}+\frac{1}{r} \frac{\partial T}{\partial r}+\frac{\partial^{2} T}{\partial z^{2}}\right)$

subject to

$w=w_{0}, \quad u=u_{w}(r)=b r, \quad T=T_{w} \quad$ at $\quad z=0$

$u=u_{e}(r) \rightarrow a r, \quad T \rightarrow T_{\infty} \quad$ as $\quad z \rightarrow \infty$.

Here $(u, 0, w)$ represent the velocity components of the hybrid nanofluid along $(r, 0, z)$ axes, $w_{0}$ denotes the constant mass flow, $T$ is the temperature of the hybrid nanofluid and $a$ is the positive strain rate of the stagnation-point flow. Further, $\mu_{h n f}$ is the dynamic viscosity of the hybrid nanofluids, $\rho_{h n f}$ is the density of the hybrid nanofluids, $k_{h n f}$ is the thermal conductivity of the hybrid nanofluid and $\left(\rho C_{\rho}\right)_{h n f}$ is the heat capacity of the hybrid nanofluid. The physical features of nanofluids and hybrid nanofluids are given in Table 1 where $\phi$ is the nanoparticle volume fraction ( $\phi=0$ reflects the base fluid), $\rho_{f}$ and $\rho_{s}$ are the densities of the base fluid and the hybrid nanoparticle, respectively, $C_{\rho}$ is the heat capacity at the constant pressure, $\left(\rho C_{\rho}\right)_{f}$ and $\left(\rho C_{\rho}\right)_{s}$ are the heat capacitance of the base fluid and the hybrid nanoparticle, respectively whereas $k_{f}$ and $k_{s}$ are the thermal conductivities of the base fluid and the hybrid nanoparticles, respectively. Then, the physical properties of copper $\mathrm{Cu}$ and alumina $\mathrm{Al}_{2} \mathrm{O}_{3}$ nanoparticles as well as the base fluid (water) are provided in Table 2 . 


\section{Table 1}

Physical features of conventional nanofluids and hybrid nanofluids

\begin{tabular}{lll}
\hline Properties & Nanofluid & Hybrid nanofluid \\
\hline Density & $\rho_{n f}=(1-\phi) \rho_{f}+\phi \rho_{s}$ & $\rho_{\text {hnf }}=\left\{\left(1-\phi_{2}\right)\left[\left(1-\phi_{1}\right) \rho_{f}+\phi_{1} \rho_{s 1}\right]\right\}+\phi_{2} \rho_{s 2}$ \\
Heat Capacity & $\left(\rho C_{p}\right)_{n f}=(1-\phi)\left(C_{p}\right)_{f}+\phi\left(\rho C_{p}\right)_{s}$ & $\left(\rho C_{p}\right)_{h n f}=\left\{\left(1-\phi_{2}\right)\left[\left(1-\phi_{1}\right)\left(\rho C_{p}\right)_{f}+\phi_{1}\left(\rho C_{p}\right)_{s 1}\right]\right\}$ \\
Viscosity & $\mu_{n f}=\frac{\mu_{f}}{(1-\phi)^{2.5}}$ & $\phi_{2}\left(\rho C_{p}\right)_{s 2}$
\end{tabular}

Table 2

Thermophysical features of the nanoparticles and base fluid

\begin{tabular}{llll}
\hline Properties & Water $(f)$ & $\mathrm{Al}_{2} \mathrm{O}_{3}\left(\phi_{1}\right)$ & $\mathrm{Cu}\left(\phi_{2}\right)$ \\
\hline$\rho\left(\mathrm{kg} / \mathrm{m}^{3}\right)$ & 997.0 & 3970 & 8933 \\
$C_{p}(J / \mathrm{kgK})$ & 4180 & 765 & 385 \\
$k(\mathrm{~W} / \mathrm{mK})$ & 0.6071 & 40 & 400 \\
\hline
\end{tabular}

We introduce now, the following similarity variables [29]

$u=\operatorname{arf}^{\prime}(\eta), \quad w=-2 \sqrt{a v_{f}} f(\eta), \quad \theta(\eta)=\frac{T-T_{\infty}}{T_{w}-T_{\infty}}, \quad \eta=z \sqrt{\frac{a}{v_{f}}}$

where prime symbolizes differentiation with respect to $\eta$. Furthermore,

$w_{0}=-\sqrt{a v_{f}} S$

where $S$ is the mass flux parameter with for $S>0$ suction and $S<0$ for injection, respectively. By implying the similarity variables (5), Eq. (2) and Eq. (3) are reduced into the ordinary differential equations as follows

$$
\begin{aligned}
& \frac{\mu_{h n f} / \mu_{f}}{\rho_{h n f} / \rho_{f}} f^{\prime \prime \prime}+2 f f^{\prime \prime}-f^{\prime 2}+1=0 \\
& \frac{1}{\operatorname{Pr}} \frac{k_{h n f} / k_{f}}{\left(\rho C_{\rho}\right)_{h n f} /\left(\rho C_{p}\right)_{f}} \theta^{\prime \prime}+2 f \theta^{\prime}=0
\end{aligned}
$$

correspond to the boundary conditions 
$f(0)=S, \quad f^{\prime}(0)=\lambda, \quad \theta(0)=1$

$f^{\prime}(\eta) \rightarrow 1, \quad \theta(\eta) \rightarrow 0 \quad$ as $\quad \eta \rightarrow \infty$

where $\operatorname{Pr}=\frac{\mu_{f}\left(C_{p}\right)_{f}}{k_{f}}$ Prandtl number. Besides, $\lambda=\frac{b}{a}$ is the stretching/shrinking parameter where $\lambda>0$ represents stretching sheet while $\lambda<0$ physically means the sheet is shrunk. In addition, $\lambda=0$ shows that the sheet is static.

The physical quantities of interest are the radial skin friction along the surface of the sheet $\bar{\tau}_{r}$ and the heat flux from the surface of the sheet $\bar{q}_{r}$, which are defined as

$\bar{\tau}_{r}=\mu_{h n f}\left(\frac{\partial u}{\partial z}\right)_{z=0}, \quad \bar{q}_{r}=-k_{h n f}\left(\frac{\partial T}{\partial z}\right)_{z=0}$

Using Eq. (5), we get the dimensionless radial skin friction along the sheet $\tau_{r}$ and dimensionless heat flux from the sheet, as

$\tau_{r}=\frac{\mu_{h n f}}{\mu_{f}} f^{\prime \prime}(0), \quad q_{r}=-\frac{k_{h n f}}{k_{f}} \theta^{\prime}(0)$

where $\tau_{r}=\frac{\bar{\tau}_{r}}{\rho_{f} \mu_{f} \sqrt{v_{f} a^{3} r}}$ and $q_{r}=\frac{\bar{q}_{r}}{k_{f}\left(T_{w}-T_{\infty}\right) \sqrt{a / v_{f}}}$.

\section{Results and Discussions}

As the first step, it is necessary to transform the partial differential Eq. (1)-(3) into the first order system of ordinary differential equations. After that, the ordinary differential equations for Eq. (7) and Eq. (8) together with boundary conditions (9) were numerically solved by executing the programming codes of boundary value problem solver (bvp4c) through MATLAB software in order to obtain the numerical solutions. The exact dual solutions only been obtained until the asymptotic results appeared through selection of an appropriate initial guess value. Then, the graphical results for the velocity profile, temperature profile, reduced skin friction coefficient and reduced Nusselt number for each involved parameters such as suction parameter and nanoparticle volume fraction ( $\phi_{1}$ and $\phi_{2}$ ) are generated. Figure 2 and Figure 3 portray the influence of suction parameter on the velocity and temperature profiles respectively. It is noticed that Figure 2 shows a rising of the velocity profile of hybrid nanofluids as an escalation in the value of suction parameter but the second solution shows the opposite behaviour which reducing the fluid flow's velocity profile. In Figure 3, both solutions are showing the same trend where the thermal boundary layer thickness is decreasing when the greater suction parameter imposed. 


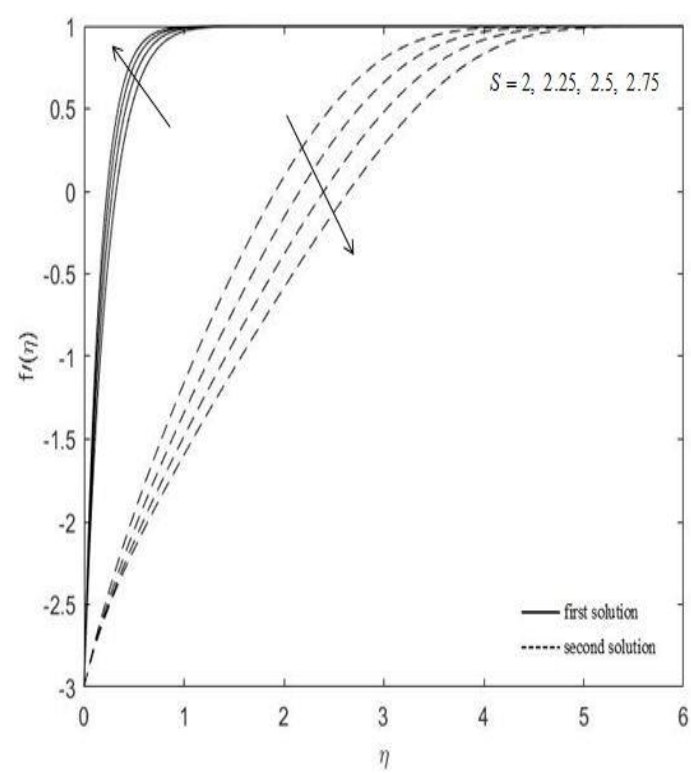

Fig. 2. The trend of velocity profile $f^{\prime}(\eta)$ with variation in $S$

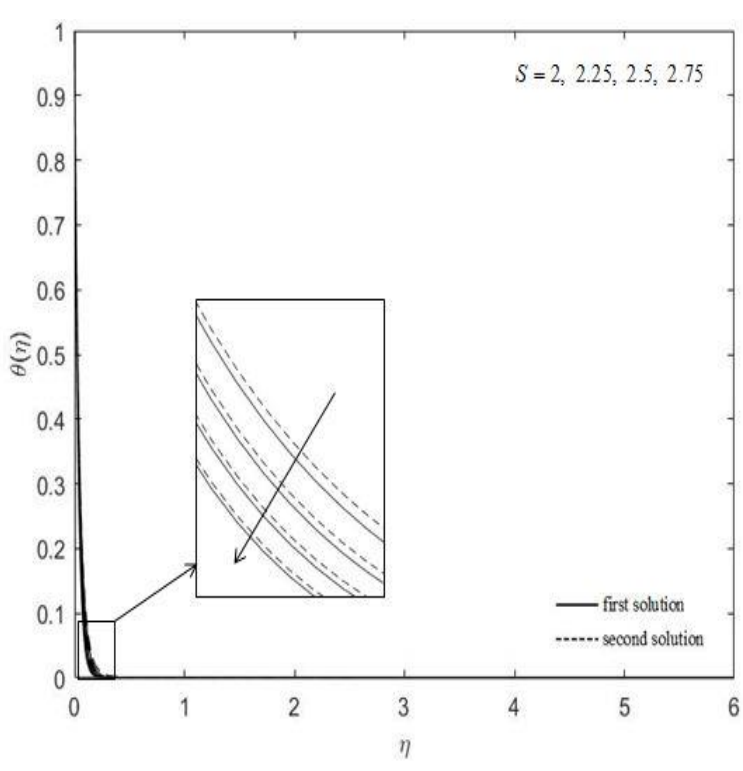

Fig. 3. The trend of temperature profile $\theta(\eta)$ with variation in $S$

The trend of velocity profile with variation in $\mathrm{Cu}$ nanoparticle volume fraction decreases for second solution but increase for the first solution as presented in Figure 4. Due to the rise in shear stress and subsequently shrinks the momentum boundary layer thickness, the fluid flow velocity is declining. The impact of variations in $\mathrm{Cu}$ nanoparticles concentration on the temperature profile showing the prominent increment for both solutions as exhibited in Figure 5 . Since the convective heat transfer has been reduced, the heat is then transfer from heated hybrid nanofluid to the hot uppermost layer and resulted temperature increase in the both solutions.

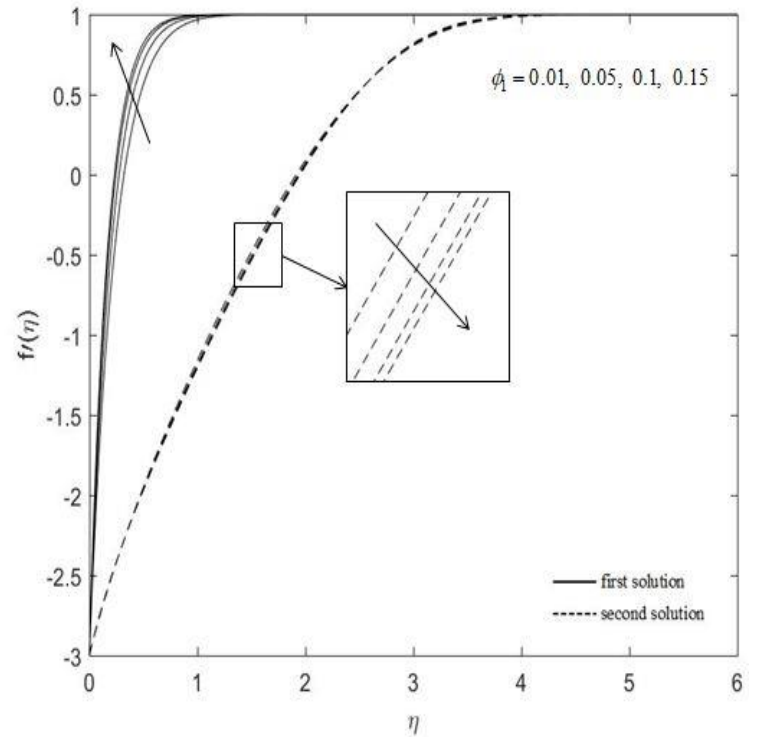

Fig. 4. The trend of $f^{\prime}(\eta)$ with variation in $\mathrm{Cu}$ nanoparticle volume fraction

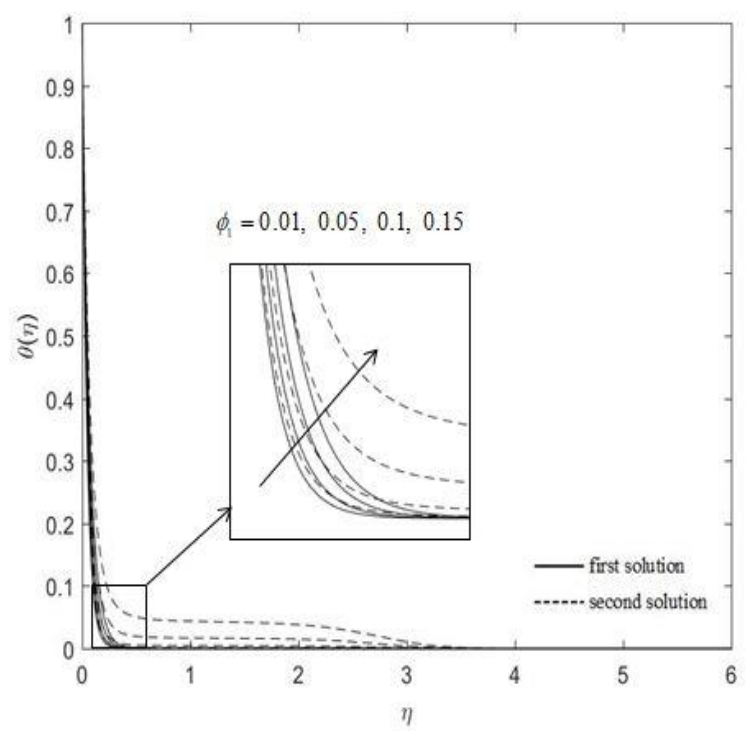

Fig. 5. The trend of $\theta(\eta)$ with variation in $\mathrm{Cu}$ nanoparticle volume fraction 
On the other hand, Figure 6 and Figure 7 illustrate the trends of velocity and temperature profile for alumina nanoparticle volume fraction, respectively. The velocity profile increases in second solutions but having opposite behaviour in the first solution as appeared asymptotically in Figure 6 and it is noticed that the thickness of momentum boundary layer for the first solution is lower if compared to the second solution. Incidentally, the profile of temperature displays the same trend in which increases as the alumina nanoparticle volume fraction increases. It reveals that the thickness of thermal boundary layer is getting higher with the increase of alumina nanoparticles.

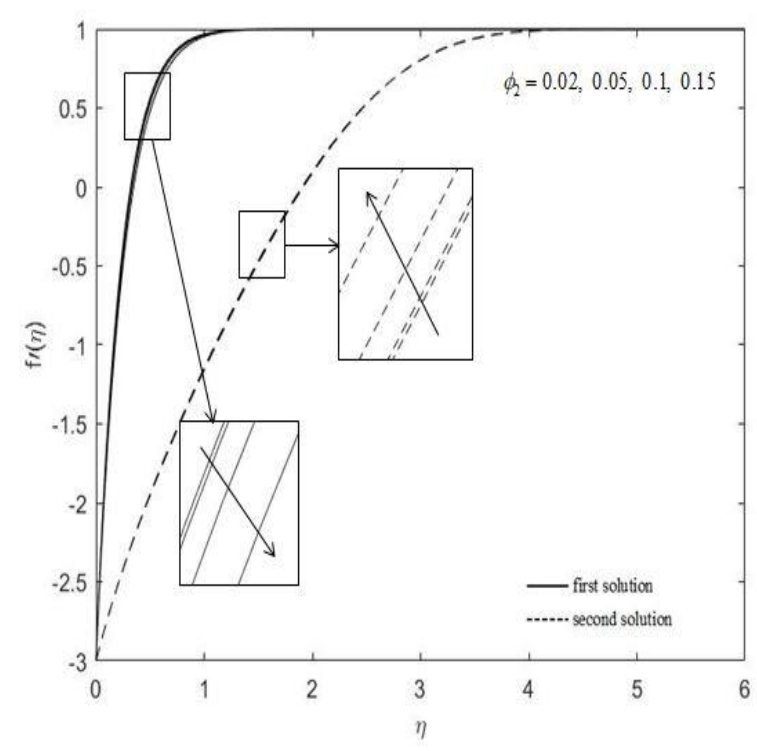

Fig. 6. The trend of $f^{\prime}(\eta)$ with variation in $\mathrm{Al}_{2} \mathrm{O}_{3}$ nanoparticle volume fraction

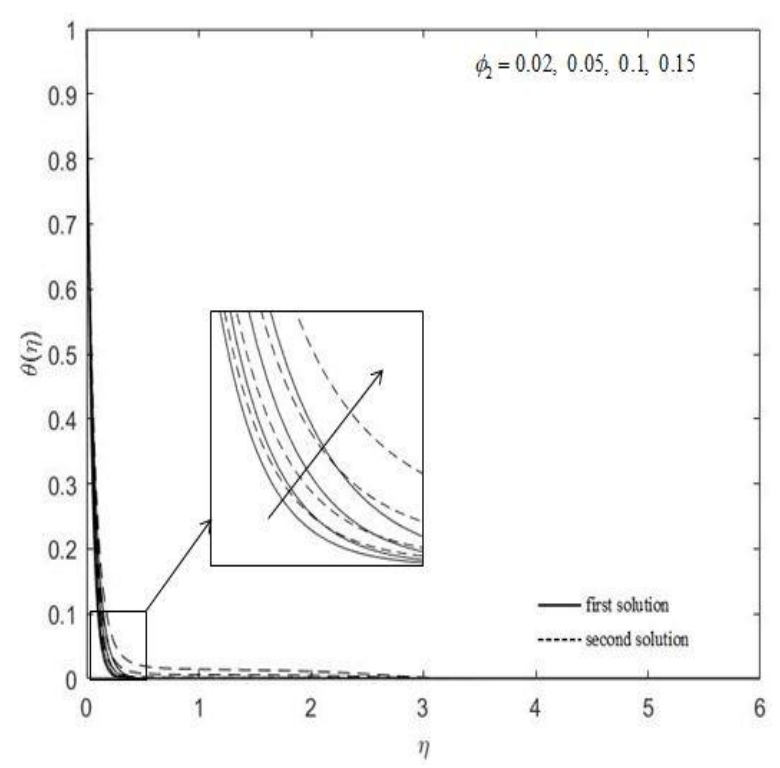

Fig. 7. The trend of $\theta(\eta)$ with variation in $\mathrm{Al}_{2} \mathrm{O}_{3}$ nanoparticle volume fraction

Figure 8 and Figure 9 depict the influence of suction parameter on reduced skin friction coefficient and reduced Nusselt number for dual solutions, respectively. As shown in the both figures, we noticed that there is a unique solution exists up for different values of suction parameter. Furthermore, there is no existence of the solutions if the $\lambda$ less than $\lambda_{c}$. The values of $\lambda_{c}$ are -4.3259 , -5.8191 and -7.5934 which correspond to $S$ equals to $2,2.5$ and 3, respectively. It is apparently shown that the increment of $S$ which leads to rise of the boundary layer separation in dual solutions, increasing $\left|f^{\prime \prime}(0)\right|$ at all the time as in Figure 8. Since the suction gives rise to more resistance in the fluid flow and causes the thickness of boundary layer become thicken, thus consequently the skin friction coefficient increases rapidly. However, the first solution shows us that the skin friction coefficient drops back slightly and retard once getting closer with the $\lambda_{c}$. There is a peculiar behaviour shown in Figure 8 (second solution for $S=2.5$ ) and this is due to the retardation at specific values of $\lambda$. For Figure 9, the reduced Nusselt number decrease slowly as increment of suction parameter. The temperature gradient decreases and reduces the thickness of boundary layer which help the hybrid nanofluid to transfer the heat effortlessly. Also, it is worth to notice that the $-\theta^{\prime}(0)$ has slow response in the beginning but increases extremely starting from $\lambda<-2$. 


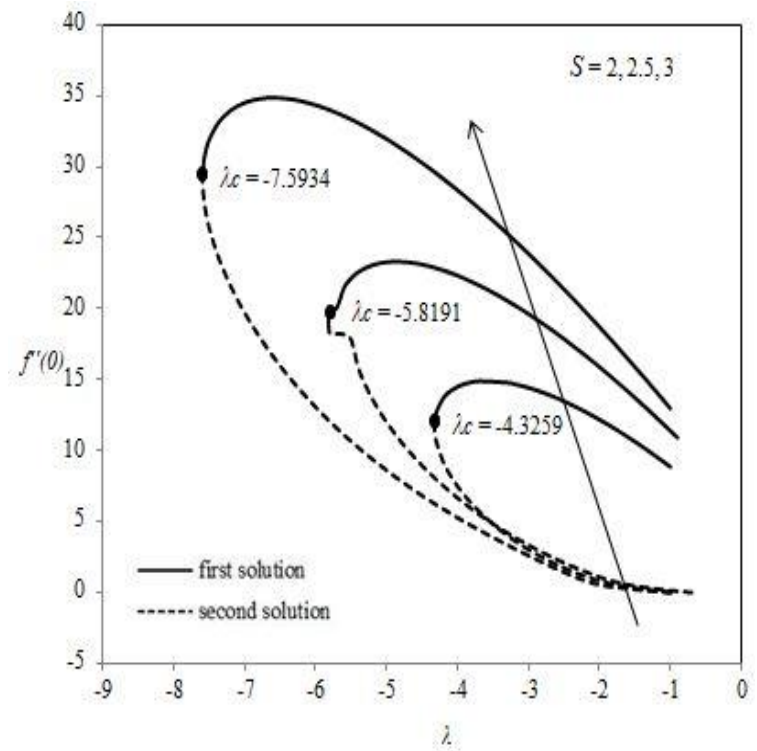

Fig. 8. The trend of $f^{\prime \prime}(0)$ with $\lambda$ for several values of $S$

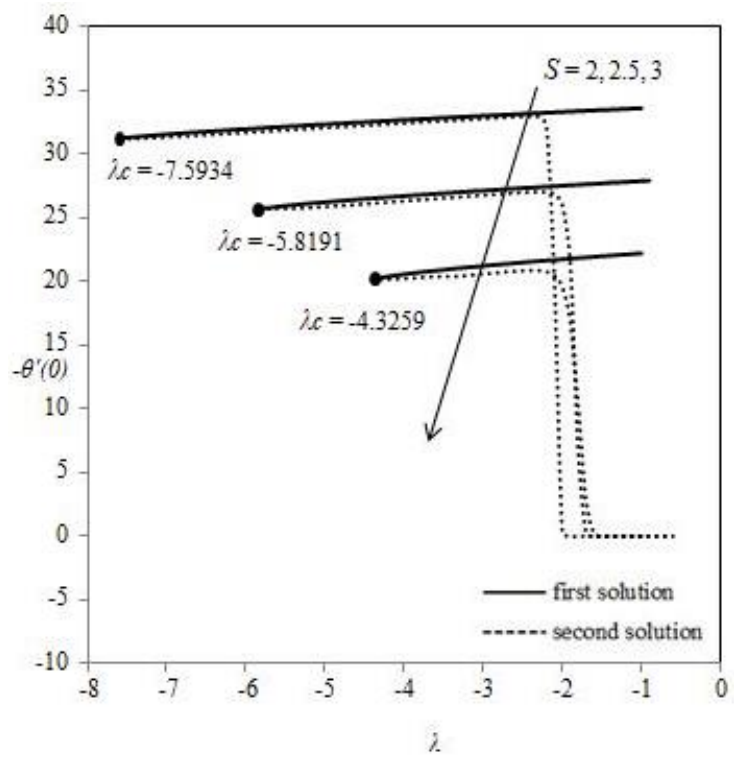

Fig. 9. The trend of $-\theta^{\prime}(0)$ with $\lambda$ for various value of $S$

Figure 10 and Figure 11 illustrate the effect of copper nanoparticle volume fraction $\phi_{1}$ on $\left|f^{\prime \prime}(0)\right|$ and $-\theta^{\prime}(0)$ respectively. The values of $\lambda_{c}$ are $-5.5369,-5.9501$ and -6.6125 which correspond to $\phi_{1}$ equals to $0.05,0.1$ and 0.15 , respectively. In Figure 10, the greater value of $\phi_{1}$ reflects to the lower value of $\lambda_{c}$. In addition, by adding up the value of $\phi_{1}$ results in the increase of $\left|f^{\prime \prime}(0)\right|$ for all the time in both solutions. Normally, the increment of nanoparticle volume fraction indicates a rapid increase of the movement and vibration of the nanoparticles in the fluid flow, thus expecting more heat energy to be released. Nevertheless, this phenomenon is contradictory proven in Figure 11 where the reduced Nusselt number lessen as $\phi_{1}$ getting higher. The heat transfer rate decreases slowly when the nanoparticles concentration increases.

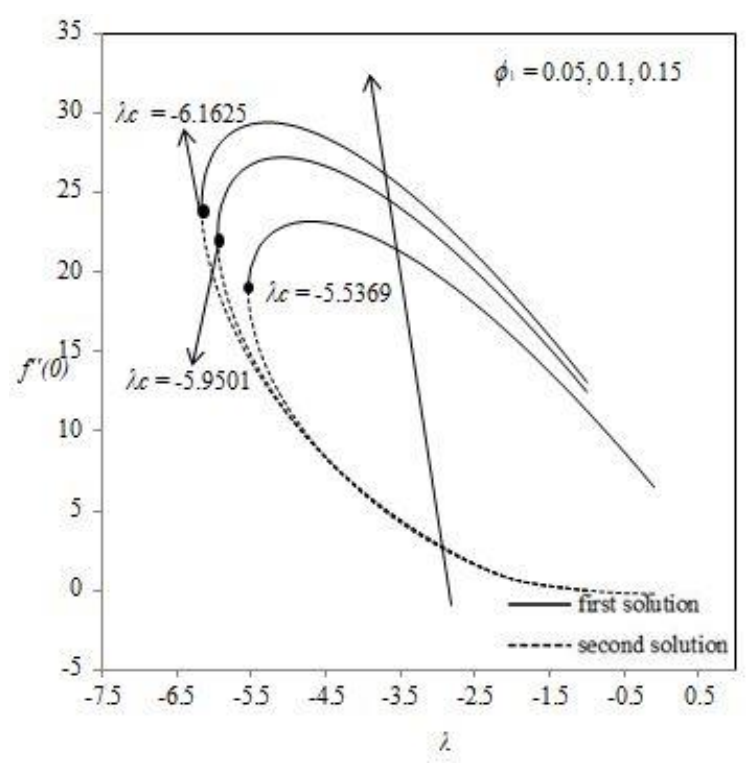

Fig. 10. Variations of $f^{\prime \prime}(0)$ for several value of Cu nanoparticle volume fraction

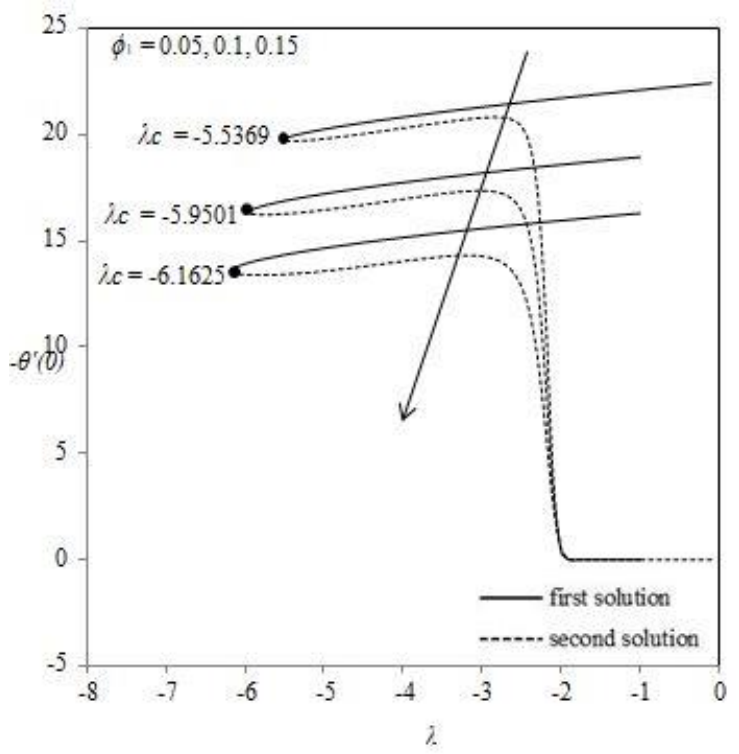

Fig. 11. Variation of $-\theta^{\prime}(0)$ for several value of Cu nanoparticle volume fraction 
Figure 12 and Figure 13 present the effect of alumina nanoparticle volume fraction $\phi_{2}$ on $\left|f^{\prime \prime}(0)\right|$ and $-\theta^{\prime}(0)$ respectively. The values of $\lambda_{c}$ are $-5.0245,-4.9476$ and -4.8120 where correspond to $\phi_{2}$ equal to $0.05,0.1$ and 0.15 , respectively. For Figure 12, it is noticed that the greater the value of $\phi_{2}$, the higher the value of $\lambda_{c}$ which is opposite behaviour from copper. This means that the higher concentration of alumina contributes to the earlier boundary layer separation. Also, a rise in in $\phi_{2}$ causes the decrement of $\left|f^{\prime \prime}(0)\right|$ for the dual solutions and slightly decreases the reduced Nusselt number as shown in Figure 13.

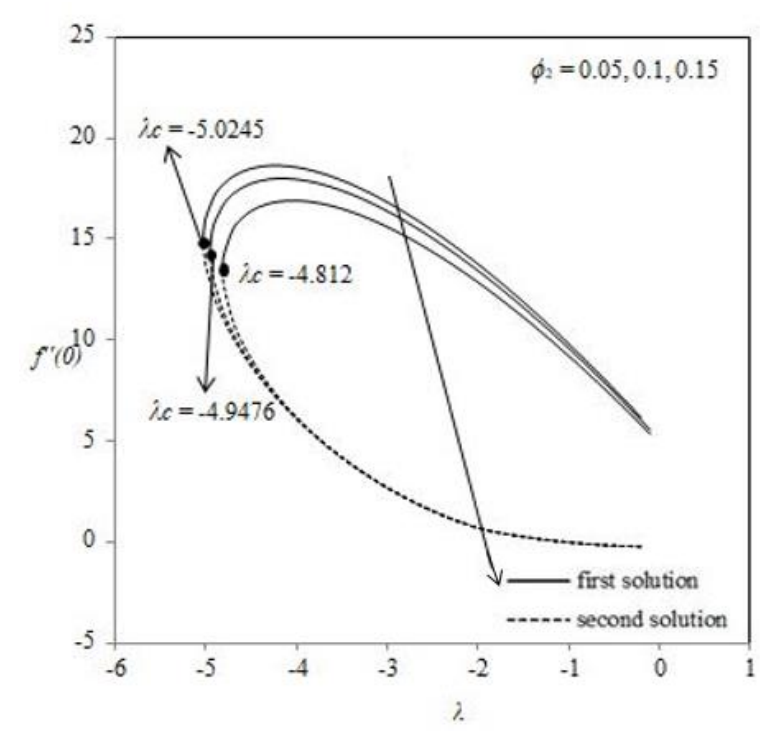

Fig. 12. Variations of $f^{\prime \prime}(0)$ for several value of Cu nanoparticle volume fraction

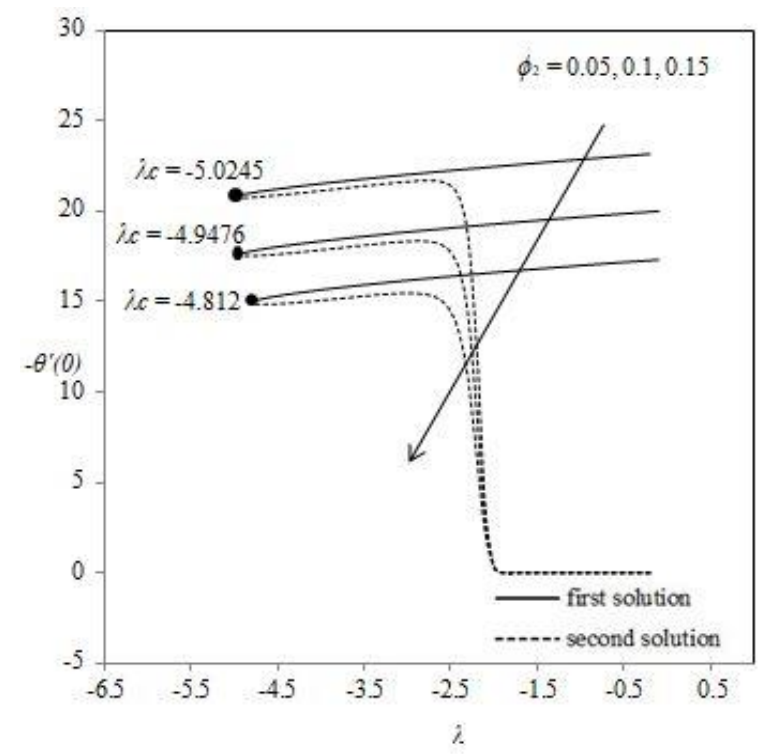

Fig. 13. Variation of $-\theta^{\prime}(0)$ for several value of Cu nanoparticle volume fraction

\section{Conclusions}

The problem of steady two-dimensional Homann stagnation point flow and heat transfer of water-based hybrid nanofluids over a permeable radially stretching/shrinking sheet has been solved numerically. The important of finding results and prominent effects are summarised as follows

i. The suction parameter caused the increment of velocity profile but in contrary reduced the temperature profile and thermal boundary layer thickness.

ii. The velocity profiles for $\mathrm{Cu}$ and $\mathrm{Al}_{2} \mathrm{O}_{3}$ nanoparticle volume fraction showed the opposite trend in dual solutions.

iii. $\mathrm{Cu}$ and $\mathrm{Al}_{2} \mathrm{O}_{3}$ nanoparticle volume fraction enlarged the thickness of boundary layer in temperature profile for both solutions.

iv. The presence of higher concentration Cu nanoparticles led to a rise in the reduced skin friction coefficient but a contradict trend was observed for $\mathrm{Al}_{2} \mathrm{O}_{3}$ nanoparticles. However, both nanoparticles contributed to a decrement in the reduced Nusselt number.

\section{Acknowledgement}

The authors sincerely would like to manifest the appreciations to Universiti Malaysia Pahang for providing the research grants (RDU191101, RDU1903143 \& RDU210703) in supporting this work. 


\section{References}

[1] Prasher, Ravi, David Song, Jinlin Wang, and Patrick Phelan. "Measurements of nanofluid viscosity and its implications for thermal applications." Applied Physics Letters 89, no. 13 (2006): 133108. https://doi.org/10.1063/1.2356113

[2] Li, Yanjiao, Simon Tung, Eric Schneider, and Shengqi Xi. "A review on development of nanofluid preparation and characterization." Powder Technology 196, no. 2 (2009): 89-101. https://doi.org/10.1016/j.powtec.2009.07.025

[3] Choi, S. US, and Jeffrey A. Eastman. "Enhancing thermal conductivity of fluids with nano-particles." ASME, FED 231 (1995): 99-105.

[4] Yu, Wenhua, David M. France, Jules L. Routbort, and Stephen US Choi. "Review and comparison of nanofluid thermal conductivity and heat transfer enhancements." Heat Transfer Engineering 29, no. 5 (2008): $432-460$. https://doi.org/10.1080/01457630701850851

[5] Jang, Seok Pil, and Stephen US Choi. "Effects of Various Parameters on Nanofluid Thermal Conductivity." Journal of Heat Transfer 129 (2007): 617-623. https://doi.org/10.1115/1.2712475

[6] Nnanna, AG Agwu. "Experimental model of temperature-driven nanofluid." Journal of Heat Transfer 129, no. 6 (2007): 697-704. https://doi.org/10.1115/1.2717239

[7] Khan, W. A., and I. Pop. "Boundary-layer flow of a nanofluid past a stretching sheet." International Journal of Heat and Mass Transfer 53, no. 11-12 (2010): 2477-2483. https://doi.org/10.1016/i.ijheatmasstransfer.2010.01.032

[8] Evans, William, Jacob Fish, and Pawel Keblinski. "Role of Brownian motion hydrodynamics on nanofluid thermal conductivity." Applied Physics Letters 88, no. 9 (2006): 093116. https://doi.org/10.1063/1.2179118

[9] Kumar, D. Dhinesh, and A. Valan Arasu. "A comprehensive review of preparation, characterization, properties and stability of hybrid nanofluids." Renewable and Sustainable Energy Reviews 81 (2018): 1669-1689. https://doi.org/10.1016/j.rser.2017.05.257

[10] Hayat, Tanzila, and S. Nadeem. "Heat transfer enhancement with Ag-CuO/water hybrid nanofluid." Results in Physics 7 (2017): 2317-2324. https://doi.org/10.1016/j.rinp.2017.06.034

[11] Dinarvand, Saeed, Mohammadreza Nademi Rostami, and Ioan Pop. "A novel hybridity model for $\mathrm{TiO}_{2}-\mathrm{CuO}_{\mathrm{O}}$ water hybrid nanofluid flow over a static/moving wedge or corner." Scientific Reports 9, no. 1 (2019): 1-11. https://doi.org/10.1038/s41598-019-52720-6

[12] Benedict, F., Amit Kumar, K. Kadirgama, Hussein A. Mohammed, D. Ramasamy, M. Samykano, and R. Saidur. "Thermal performance of hybrid-inspired coolant for radiator application." Nanomaterials 10, no. 6 (2020): 1100. https://doi.org/10.3390/nano10061100

[13] Huang, Dan, Zan Wu, and Bengt Sunden. "Effects of hybrid nanofluid mixture in plate heat exchangers." Experimental Thermal and Fluid Science 72 (2016): 190-196. https://doi.org/10.1016/i.expthermflusci.2015.11.009

[14] Sinz, C. K., H. E. Woei, M. N. Khalis, and S. I. Ali Abbas. "Numerical study on turbulent force convective heat transfer of hybrid nanofluid, Ag/HEG in a circular channel with constant heat flux." Journal of Advanced Research in Fluid Mechanics and Thermal Sciences 24, no. 1 (2016): 1-11.

[15] Xian, Hong Wei, Nor Azwadi Che Sidik, Siti Rahmah Aid, Tan Lit Ken, and Yutaka Asako. "Review on preparation techniques, properties and performance of hybrid nanofluid in recent engineering applications." Journal of Advanced Research in Fluid Mechanics and Thermal Sciences 45, no. 1 (2018): 1-13.

[16] Urmi, Wajiha Tasnim, A. S. Shafiqah, Md Mustafizur Rahman, Kumaran Kadirgama, and Md Abdul Maleque. "Preparation Methods and Challenges of Hybrid Nanofluids: A Review." Journal of Advanced Research in Fluid Mechanics and Thermal Sciences 78, no. 2 (2020): 56-66. https://doi.org/10.37934/arfmts.78.2.5666

[17] Azman, Azraf, Mohd Zamri Yusoff, Azfarizal Mukhtar, Prem Gunnasegaran, Nasri A. Hamid, and Ng Khai Ching. "Numerical Study of Heat Transfer Enhancement for Mono and Hybrid Nanofluids Flow in a Straight Pipe." CFD Letters 13, no. 2 (2021): 49-61. https://doi.org/10.37934/cfdl.13.2.4961

[18] Idris, Muhammad Syafiq, Irnie Azlin Zakaria, and Wan Azmi Wan Hamzah. "Heat Transfer and Pressure Drop of Water Based Hybrid $\mathrm{Al}_{2} \mathrm{O}_{3}$ : $\mathrm{SiO}_{2}$ Nanofluids in Cooling Plate of PEMFC." Journal of Advanced Research in Numerical Heat Transfer 4, no. 1 (2021): 1-13.

[19] Roşca, Alin V., and loan Pop. "Flow and heat transfer over a vertical permeable stretching/shrinking sheet with a second order slip." International Journal of Heat and Mass Transfer 60 (2013): 355-364. https://doi.org/10.1016/i.ijheatmasstransfer.2012.12.028

[20] Sakiadis, Byron C. "Boundary-layer behavior on continuous solid surfaces: I. Boundary-layer equations for twodimensional and axisymmetric flow." AIChE Journal 7, no. 1 (1961): 26-28. https://doi.org/10.1002/aic.690070108

[21] Crane, Lawrence J. "Flow past a stretching plate." Zeitschrift für angewandte Mathematik und Physik ZAMP 21, no. 4 (1970): 645-647. https://doi.org/10.1007/BF01587695

[22] Miklavčič, M., and C. Wang. "Viscous flow due to a shrinking sheet." Quarterly of Applied Mathematics 64, no. 2 (2006): 283-290. https://doi.org/10.1090/S0033-569X-06-01002-5 
[23] Bachok, Norfifah, Anuar Ishak, and loan Pop. "Stagnation-point flow over a stretching/shrinking sheet in a nanofluid." Nanoscale Research Letters 6, no. 1 (2011): 1-10. https://doi.org/10.1186/1556-276X-6-623

[24] Waini, Iskandar, Anuar Ishak, and loan Pop. "Unsteady flow and heat transfer past a stretching/shrinking sheet in a hybrid nanofluid." International Journal of Heat and Mass Transfer 136 (2019): 288-297. https://doi.org/10.1016/j.ijheatmasstransfer.2019.02.101

[25] Hiemenz, Karl. "Die Grenzschicht an einem in den gleichformigen Flussigkeitsstrom eingetauchten geraden Kreiszylinder." Dinglers Polytech. J. 326 (1911): 321-324.

[26] Homann, Fritz. "Der Einfluss grosser Zähigkeit bei der Strömung um den Zylinder und um die Kugel." ZAMM-Journal of Applied Mathematics and Mechanics/Zeitschrift für Angewandte Mathematik und Mechanik 16, no. 3 (1936): 153-164. https://doi.org/10.1002/zamm.19360160304

[27] Yousefi, Mohammad, Saeed Dinarvand, Mohammad Eftekhari Yazdi, and loan Pop. "Stagnation-point flow of an aqueous titania-copper hybrid nanofluid toward a wavy cylinder." International Journal of Numerical Methods for Heat \& Fluid Flow 28, no. 7 (2018): 1716-1735. https://doi.org/10.1108/HFF-01-2018-0009

[28] Ghalambaz, Mohammad, Natalia C. Roşca, Alin V. Roşca, and Ioan Pop. "Mixed convection and stability analysis of stagnation-point boundary layer flow and heat transfer of hybrid nanofluids over a vertical plate." International Journal of Numerical Methods for Heat \& Fluid Flow 30, no. 7 (2019): 3737-3754. https://doi.org/10.1108/HFF-08$\underline{2019-0661}$

[29] Weidman, P. D., and Yi Ping Ma. "The competing effects of wall transpiration and stretching on Homann stagnationpoint flow." European Journal of Mechanics-B/Fluids $60 \quad$ (2016): $237-241$. https://doi.org/10.1016/j.euromechflu.2016.07.003

[30] Mahapatra, T. R., and S. Sidui. "Non-axisymmetric Homann stagnation-point flow of a viscoelastic fluid towards a fixed plate." European Journal of Mechanics-B/Fluids $79 \quad$ (2020): 38-43. https://doi.org/10.1016/i.euromechflu.2019.08.010

[31] Butt, Adnan Saeed, and Asif Ali. "Entropy analysis of magnetohydrodynamic flow and heat transfer over a convectively heated radially stretching surface." Journal of the Taiwan Institute of Chemical Engineers 45, no. 4 (2014): 1197-1203. https://doi.org/10.1016/i.jtice.2014.02.019 